\title{
Transcriptional profiling reveals molecular basis and novel genetic targets for improved resistance to multiple fermentation inhibitors in Saccharomyces cerevisiae
}

\author{
Yingying Chen ${ }^{1 \dagger}$, Jiayuan Sheng ${ }^{2 \dagger}$, Tao Jiang ${ }^{3}$, Joseph Stevens ${ }^{2}$, Xueyang Feng ${ }^{2^{*}}$ and Na Wei ${ }^{1^{*}}$
}

\begin{abstract}
Background: Lignocellulosic biomass is a promising source of renewable biofuels. However, pretreatment of lignocellulosic biomass generates fermentation inhibitors that adversely affect the growth of industrial microorganisms such as Saccharomyces cerevisiae and prevent economic production of lignocellulosic biofuels. A critical challenge on developing S. cerevisiae with improved inhibitor resistance lies in incomplete understanding of molecular basis for inhibitor stress response and limited information on effective genetic targets for increasing yeast resistance to mixed fermentation inhibitors. In this study, we applied comparative transcriptomic analysis to determine the molecular basis for acetic acid and/or furfural resistance in S. cerevisiae.

Results: We recently developed a yeast strain YC1 with superior resistance to acetic acid, furfural, and their mixture through inverse metabolic engineering. In this study, we first determined transcriptional changes through RNA sequencing in $\mathrm{YC} 1$ versus the wild-type strain S-C1 under three different inhibitor conditions, including acetic acid alone, furfural alone, and mixture of acetic acid and furfural. The genes associated with stress responses of $\mathrm{S}$. cerevisiae to single and mixed inhibitors were revealed. Specifically, we identified 184 consensus genes that were differentially regulated in response to the distinct inhibitor resistance between $\mathrm{YC} 1$ and S-C1. Bioinformatic analysis next revealed key transcription factors (TFs) that regulate these consensus genes. The top TFs identified, Sfp $1 \mathrm{p}$ and Ace2p, were experimentally tested as overexpression targets for strain optimization. Overexpression of the SFP1 gene improved specific ethanol productivity by nearly four times, while overexpression of the ACE2 gene enhanced the rate by three times in the presence of acetic acid and furfural. Overexpression of SFP1 gene in the resistant strain YC1 further resulted in $42 \%$ increase in ethanol productivity in the presence of acetic acid and furfural, suggesting the effect of $\mathrm{Sfp} 1 \mathrm{p}$ in optimizing the yeast strain for improved tolerance to mixed fermentation inhibitor.
\end{abstract}

Conclusions: Transcriptional regulation underlying yeast resistance to acetic acid and furfural was determined. Two transcription factors, Sfp1 $p$ and Ace2p, were uncovered for the first time for their functions in improving yeast

\footnotetext{
*Correspondence: xueyang@vt.edu; nwei@nd.edu

${ }^{\dagger}$ Yingying Chen and Jiayuan Sheng have equal contributions

1 Department of Civil and Environmental Engineering and Earth Sciences,

University of Notre Dame, 106E Cushing Hall of Engineering, Notre Dame,

South Bend, IN 46556, USA

${ }^{2}$ Department of Biological Systems Engineering, Virginia Polytechnic

Institute and State University, Blacksburg, VA, USA

Full list of author information is available at the end of the article
} 
resistance to mixed fermentation inhibitors. The study demonstrated an omics-guided metabolic engineering framework, which could be developed as a promising strategy to improve complex microbial phenotypes.

Keywords: Yeast, Acetic acid, Furfural, RNA-seq, Transcription factors, Metabolic engineering

\section{Background}

Lignocellulosic biomass has the potential to contribute substantially to future global energy demands, because it is low in cost, is available at large-scale, does not compete with food production, and has high potential to reduce greenhouse gas emission [1-4]. However, inefficient conversion of solubilized plant cell wall materials into biofuels has hindered commercial scale processes. Lignocellulosic biomass materials need to undergo harsh (physico)chemical treatment designed to release sugar compounds [5, 6], but at the same time, the hydrolysis pretreatment generates toxic byproducts such as weak acids, furan aldehydes, and phenolic compounds (referred to as "fermentation inhibitors") [7-9]. A robust inhibitor resistance fermenting microorganism is critically important for developing economically viable lignocellulosic biofuels, but this remains a major technical barrier [9].

Two major groups of fermentation inhibitors generated from pretreatment of lignocellulosic biomass are weak acids (e.g., acetic acid and formic acid) and furan aldehydes [e.g., furfural and 5-hydroxy methylfurfural (HMF)] $[9,10]$. Particularly, since hemicellulose in the plant cell wall is ubiquitously acetylated [11,12], typical acidic pretreatment of lignocellulosic biomass generates substantial amounts of acetic acid as an unavoidable fermentation inhibitor in hydrolysates $[7,13]$ and acetic acid is usually of the highest concentration among fermentation inhibitors in cellulosic hydrolysates [7, 14-18]. Furfural and HMF are major byproducts generated from hydrolysis and dehydration of pentose and hexose sugars $[9,10]$.

The yeast Saccharomyces cerevisiae is a preferred and widely used platform microorganism in industrial fermentation, but the toxic nature of cellulosic hydrolysates and low tolerance of the microorganism prevent efficient bioethanol production from cellulosic sugars $[19,20]$. Uptake of weak acids decreases intracellular $\mathrm{pH}$, which triggers the action of the plasma membrane ATPase to pump protons out of the cell at the expenses of ATP hydrolysis [21-24]. In addition, weak acids also cause intracellular anion accumulation, which interferes with enzymatic reactions and causes toxicity [25, 26]. Furan aldehydes inhibit enzymes of central carbon metabolism [27-29] and energy metabolism [30], and cause depletion of $\mathrm{NAD}(\mathrm{P}) \mathrm{H}$ pools and oxidative stress [10, 31-33]. The key challenge of engineering inhibitor-resistant yeast lies in that the resistance phenotype usually involves complex multi-genic regulations among disparate stress responses.

There have been significant advances in determining inhibitor stress response mechanisms for improving yeast resistance to individual fermentation inhibitors $[9$, 34]. For example, resistance to furan aldehydes could be enhanced by overexpressing genes related to aldehyde reduction [35, 36], spermidine synthesis [37], pentose phosphate pathway $[38,39]$, or multidrug resistance and stress responses $[9,40]$. As for tolerance to weak acids such as acetic acid, analysis of transcriptional response of $S$. cerevisiae to acetic acid stress showed up-regulation of various genes involved in glycolysis, the Krebs cycle and ATP synthesis [41-43] and the important role of the transcription factor Haalp in regulating the cell-wide transcriptional adaptation to acetic acid in yeast [42, 44, 45]. Genetic targets related to resistance to individual fermentation inhibitors in S. cerevisiae were reported in some previous studies [46, 47]. For example, earlier studies found that overexpression of Msn2p [46] and Yap1p [48] could improve furfural resistance in the yeast. While prior studies are mostly focused on characterization of genetic mechanisms for yeast stress response to individual inhibitory compounds, cellulosic hydrolysates contain mixed fermentation inhibitors with distinct toxicity mechanisms rather than a single inhibitor. Some recent works reported improved yeast resistance to cellulosic hydrolysates through evolutionary engineering [49-51], and systematic analysis was used in previous studies to understand molecular basis for yeast inhibitor resistance [51-56]. It was found that different mechanisms could be adopted by the yeast to resist hydrolysates inhibitors (e.g. acetic acid, furfural, and HMF) [51]. However, there is still limited information on what genetic perturbation targets could be elicited to improve yeast resistance to mixed fermentation inhibitors. Therefore, a better understanding of genetic regulatory networks underlying the resistance to mixed fermentation inhibitors in S. cerevisiae is needed to develop strains with enhanced tolerance to cellulosic hydrolysates.

We recently developed a yeast strain that has superior inhibitor resistance through inverse metabolic engineering [57]. In the present study, we performed comparative transcriptomic analysis using RNA deep sequencing (RNA-seq) to determine transcriptional response in S. cerevisiae to acetic acid and/or furfural, 
and to identify key transcription factors (TFs) that regulate tolerance to mixed inhibitors in the yeast. First, the genome-wide transcriptional changes in the resistant strain versus the wild-type control strain were identified by transcriptomic analysis under three different inhibitor conditions, including acetic acid alone, furfural alone, and mixture of acetic acid and furfural. Then, the TFs that regulate the core genes with significant changes in expression under stress of both inhibitors were identified and top TFs were tested experimentally as overexpression targets for strain optimization. Our results advance fundamental understanding of the genetic regulatory mechanisms underlying yeast resistance to major fermentation inhibitors in cellulosic hydrolysates. We also report novel transcription factors involved in regulating resistance to mixed inhibitor stress. The transcriptome-guided metabolic engineering demonstrated here could be a promising strategy to improve complex phenotypes in yeast, particularly in the cases where coordinated reprogramming of a number of genes is needed.

\section{Materials}

\section{Strains and plasmids}

All the strains and plasmids used in this study are summarized in Table 1 . The S. cerevisiae strains SR8, SR8-trp, and SR8-4 were kindly provided by Dr. Yong-Su Jin's lab. The strain SR8-trp was transformed with yeast genomic DNA library on a multicopy plasmid pRS424 and a yeast transformant YC1 with improved resistance to acetic acid, and furfural was obtained through the inverse metabolic engineering approach in our recent work [57]. The Escherichia coli TOP10 strain was used for gene cloning and manipulation.

\section{Enzymes, primers, and chemicals}

Restriction enzymes, DNA-modifying enzymes, and PCR reagents were purchased from New England Biolabs (Beverly, MA, USA). The reaction conditions were set-up following the manufacturer's instructions. All general chemicals and media components were purchased from Sigma-Aldrich (St. Louis, MO, USA) or Fisher Scientific (Pittsburgh, PA, USA). Primers for both PCR and

Table 1 Plasmids and Strains

\begin{tabular}{|c|c|c|}
\hline Plasmids and strains & Description & References \\
\hline \multicolumn{3}{|l|}{ Plasmids } \\
\hline pRS424 & TRP1, a multicopy plasmid & [76] \\
\hline pRS425 & LEU2, a multicopy plasmid & {$[76]$} \\
\hline pRS424-WHI2 & $\begin{array}{l}\text { pRS424 with insert of S288c yeast genomic DNA fragment } \\
\text { chrXV: 409,259-412,369 (containing complete sequence of the WHI2 gene) }\end{array}$ & This study \\
\hline pRS424GPD & pRS424 with GPD promoter & {$[76]$} \\
\hline pRS425GPD & pRS425 with GPD promoter & {$[76]$} \\
\hline pRS424GPD-WHI2 & WHI2 expressed in pRS424GPD & This study \\
\hline pRS424GPD-SFP1 & SFP1 expressed in pRS424GPD & This study \\
\hline pRS424GPD-ACE2 & ACE2 expressed in pRS424GPD & This study \\
\hline pRS425GPD-SFP1 & SFP1 expressed in pRS425GPD & This study \\
\hline pRS425GPD-ACE2 & ACE2 expressed in Prs425GPD & This study \\
\hline \multicolumn{3}{|l|}{ Strains } \\
\hline D452-2 & MATa, leu2, his3, ura3, can 1 & {$[77]$} \\
\hline SR8 & $\begin{array}{l}\text { D452-2 expressing } X Y L 1, X Y L 2 \text {, and } X K S 1 \text { through integration, } \\
\text { evolutionary engineering in xylose-containing media, and } A L D 6 \text { deletion }\end{array}$ & [40] \\
\hline SR8-trp & SR8 with TRP1 disrupted & Developed in Dr. Yong-Su Jin lab \\
\hline SR8-4 & SR8 with TRP1, LEU2, HIS3 and URA3 disrupted & Developed in Dr. Yong-Su Jin lab \\
\hline $\mathrm{S}-\mathrm{C} 1$ & SR8-trp harboring pRS424GPD, as a control & This study \\
\hline YC1 & SR8-trp harboring pRS424-WHI2 & This study \\
\hline S- SFP1 & SR8-trp harboring pRS424GPD-SFP1 & This study \\
\hline S-ACE2 & SR8-trp harboring pRS424GPD- ACE2 & This study \\
\hline $\mathrm{S}-\mathrm{C} 2$ & SR8-4 harboring pRS424GPD and pRS425GPD, as a control & This study \\
\hline S-WHI2-C & SR8-4 harboring pRS424GPD-WHI2 and pRS425GPD & This study \\
\hline S-WHI2-SFP1 & SR8-4 harboring pRS424GPD- WHI2 and pRS425GPD- SFP1 & This study \\
\hline
\end{tabular}

The TDH3 promoter is often referred to as the GPD promoter, which is used in the pRS4XX series of expression vectors [76]

GPD stands for Glyceraldehyde-3-phosphate dehydrogenase, encoded by the TDH3 gene 
sequencing were synthesized by Integrated DNA Technologies (Coralville, IA, USA) and are listed in Table 2.

\section{Plasmid and strain construction}

To construct overexpression plasmids with different identified transcriptional factors, the complete open reading frames of transcriptional factors were amplified by PCR with the primers listed in Table 2 . The PCR products were subsequently digested and ligated to appropriate multiple cloning sites of the plasmid pRS424GPD or pSR425GPD. The overexpression vectors were transformed, respectively, to the strain SR8-trp using Yeast EZ-transformation Kit (BIO 101).

\section{Media and culture conditions}

Escherichia coli strains were grown in Luria-Bertani medium at $37^{\circ} \mathrm{C}$, and $100 \mu \mathrm{g} / \mathrm{mL}$ of ampicillin was added to the medium when required. Yeast strains were routinely cultivated at $30{ }^{\circ} \mathrm{C}$ in YP medium $(10 \mathrm{~g} / \mathrm{L}$ of yeast extract and $20 \mathrm{~g} / \mathrm{L}$ of peptone) or synthetic complete (SC) medium $(6.7 \mathrm{~g} / \mathrm{L}$ of yeast nitrogen base, $0.6 \mathrm{~g} / \mathrm{L}$ complete supplement mixture) containing $20 \mathrm{~g} / \mathrm{L}$ of D-glucose. SC media containing $20 \mathrm{~g} / \mathrm{L}$ agar and glucose, $20 \mathrm{mg} / \mathrm{L}$ histidine and uracil without tryptophan and/or leucine $(100 \mathrm{mg} / \mathrm{L}$ if needed) amendment was used to select transformants using TRP1 and/or LEU2 as auxotrophic markers.

\section{Batch fermentation experiments}

Yeast cells were pre-cultured in SC medium containing $20 \mathrm{~g} / \mathrm{L}$ glucose until stationary phase, and then were centrifuged, washed by sterilized water, and then inoculated into fermentation media containing glucose $(20 \mathrm{~g} / \mathrm{L})$, acetic acid $(2 \mathrm{~g} / \mathrm{L})$, and/or furfural $(1 \mathrm{~g} / \mathrm{L})$. Batch fermentation experiments under oxygen-limited conditions were conducted in $125 \mathrm{~mL}$ non-baffled Erlenmeyer flasks containing $20 \mathrm{~mL}$ media at $30^{\circ} \mathrm{C}$ and $100 \mathrm{rpm}$. The initial cell densities were adjusted to $\mathrm{OD}_{600}=1$ or 0.2 . The initial $\mathrm{pH}$ of the media was adjusted to 4.0. Culture samples were taken from fermentation experiments to measure

Table 2 Primers used in this study

\begin{tabular}{ll}
\hline Target & Primer sequence \\
\hline WHI2 & Forward GCCGGATCCAAAAATGGACGATATAATCACGCAAG \\
& Reverse GCCGTCGACTCACTGCACCCCAATAACGC \\
SFP1 & Forward GCCCCCGGATGGATTTTACAACAATGACTATG \\
& Reverse GCCGTCGACTTAGTGAGTGAGTGGCCCC \\
ACE2 & Forward GCCACTAGTATGGATAACGTTGTAGATCCGTG \\
& Reverse GCCGTCGACTCAGAGAGCATCAGTTTCGTTTG \\
T3 promoter & AATTAACCTCACTAAAGGG \\
T7 promoter & TAATACGACTCACTATAGGG \\
\hline
\end{tabular}

the $\mathrm{OD}_{600}$ and concentrations of metabolites. All fermentation experiments were set-up in biological duplicate.

\section{Sample preparation for RNA sequencing}

Yeast cells were grown to early exponential phase under oxygen-limited conditions in $50 \mathrm{~mL} \mathrm{SC}+$ glucose medium in $250 \mathrm{~mL}$ Erlenmeyer flasks in biological triplicate, and were exposed to different inhibitors for 4 hours before cell samples were collected for RNA-seq analysis. Four inhibitor conditions were applied for comparative transcriptomics study: (1) acetic acid (2 g/L), (2) furfural $(1 \mathrm{~g} / \mathrm{L}),(3)$ acetic acid $(2 \mathrm{~g} / \mathrm{L})+$ furfural $(1 \mathrm{~g} / \mathrm{L})$, and (4) blank control without any inhibitor. Cell samples taken from each replicate incubations were collected in pre-chilled Falcon tubes and were centrifuged at $4{ }^{\circ} \mathrm{C}$ for $1 \mathrm{~min}$. The cell pellets were flash-frozen in liquid nitrogen and stored in $-80{ }^{\circ} \mathrm{C}$ before analysis. Total RNA was extracted by PureLink RNA Mini Kitfrom Life Technology (Grand Island, NY) according to the supplier's instructions. The RNA samples were then sent to Virginia Bioinformatics Institute for further quality and quantity evaluation, cDNA library preparation, and sequencing.

\section{Analytical methods}

Fermentation metabolites including glucose, glycerol, acetic acid, and ethanol were quantified by high performance liquid chromatography (Agilent Technologies 1200 series) equipped with a refractive index detector and a Rezex ROA-Organic Acid $\mathrm{H}^{+}(8 \%)$ column (Phenomenex Inc., Torrance, CA, USA). The column was eluted with $0.005 \mathrm{~N} \mathrm{H}_{2} \mathrm{SO}_{4}$ as the mobile phase under the flow rate of $0.6 \mathrm{~mL} / \mathrm{min}$ at $50{ }^{\circ} \mathrm{C}$. Cell growth was monitored by measuring optical density at $600 \mathrm{~nm}\left(\mathrm{OD}_{600}\right)$ using UV-visible spectrophotometer (Thermo Fisher Scientific Inc., Waltham, MA, USA).

\section{RNA-seq and bioinformatics analysis}

All the library preps were performed on Apollo 324 Robot (WaferGen, Fremont, CA, USA). Quality of total RNA was checked on Agilent BioAnalyzer 2100 (Agilent Technologies, Santa Clara, CA, USA). 500 ng of total RNA was enriched for polyA RNA using PrepXPolyA mRNA Isolation Kit (P/N 400047, WaferGen, Fremont, CA, USA). PolyA RNA was then converted into a library of template molecules using PrepX RNA-Seq for Illumina Library Kit, 24 samples (P/N 400046, WaferGen, Fremont, CA, USA) for subsequent cluster generation and sequencing by Illumina HiSeq. Briefly, polyA mRNA was fragmented into smaller pieces ( 140nt). $3^{\prime}$ and $5^{\prime}$ adapters were ligated to the cleaved RNA fragments and converted to first-strand cDNA using reverse transcriptase, followed by second-strand synthesis. The products were then purified and enriched with 12 cycles of PCR 
to create the final cDNA library. The $280-300$ bp libraries (160-180 bp insert) generated were validated using Agilent 2100 Bioanalyzer and quantitated using QuantiT dsDNA HS Kit (Invitrogen) and qPCR. 12 indexed cDNA libraries were pooled and sequenced on each lane of HiSeq Rapid Run flow cell to generate 130-150 million single reads. Libraries were clustered onto a flow cell using Illumina's TruSeq Rapid SR Cluster Kit 2500 (GD-402-4001) on the cBot, and sequenced $1 \times 101$ SR cycles using two TruSeq Rapid SBS Kit (50-cycles) (FC-402-4002).

Following sequencing, data were trimmed for both adaptor and quality using a combination of ea-utils [58] and Btrim [59]. Sequencing reads were then aligned to the genome using Tophat2/Bowtie2 [60] and counted via HTSeq [61]. QC summary statistics were examined to identify any problematic samples (e.g., total read counts, quality and base composition profiles ( \pm trimming)), raw fastq formatted data files, aligned files (bam and text file containing sample alignment statistics), and count files (HTSeq text files). Following successful alignment, miRNA and mRNA differential expressions were determined and tested for significance using the BenjaminiHochberg-corrected Wald Test in the R-package DESeq2 [62]. The gene ontology analysis was performed by using generic GO term mapper developed by Princeton University (http://go.princeton.edu/cgi-bin/GOTermMapper).

\section{Quantitative PCR (qPCR) validation}

To validate the differentiated gene expressions from RNA-seq analysis, 24 samples analyzed by RNASeq were validated by TaqMan qPCR for differential expression of 3 target genes (YML038C-SC04151537, YHR127 W-SC04130738, and YJR096 W-SC04138893) and an endogenous control, YNL219C-SC04159779 (ALG9). $1.5 \mu \mathrm{g}$ of total RNA was reverse transcribed using SuperScript VILO MasterMix kit (P/N 100012386, Invitrogen). $25 \mathrm{ng}$ of cDNA was used for each TaqMan PCR reaction. Each sample with each target gene was done in triplicate. qPCR was performed using TaqMan Fast Advanced MasterMix (P/N4444557, Applied Biosystems), on ViiA7 instrument (Applied Biosystems) at $50^{\circ} \mathrm{C}$ for $2 \mathrm{~min}, 95^{\circ} \mathrm{C}$ for $20 \mathrm{~s}$ and 40 cycles at $95{ }^{\circ} \mathrm{C} 1 \mathrm{~s}$ and $60^{\circ} \mathrm{C}$ for $30 \mathrm{~s}$. Data were analyzed according to the $\Delta \Delta \mathrm{C}_{\mathrm{t}}$ method as described in the Invitrogen RT-PCR manual. The expression levels of all the target genes in qPCR analysis were found to be well correlated to those in RNA-seq analysis (Additional file 1: Figure S1).

\section{Transcription factor analysis}

To identify the transcription factors that are most likely involved in regulating yeast transcriptomics, transcription factor analysis was accomplished using a previously published method [63]. In general, the YEASTRACT database (http://www.yeastract.com/) was solicited, in which the differentially expressed genes identified by the RNA-seq analysis were searched against all of the transcription factors (TFs) in the YEASTRACT database (only documented regulations with direct or indirect evidences were taken into consideration). To provide the TF profiles, the number of genes that a TF can regulate in the pool of genes that were found to be differentially expressed was calculated by YEASTRACT database. Then, it is divided by the total number of genes that were found to be differentially expressed.

\section{Results}

\section{Fermentation under the stress of acetic acid and furfural}

We have developed an inhibitor-resistant strain YC1 (Table 1) through our prior work using a genomic librarybased inverse metabolic engineering approach [57]. Briefly, a genome-wide plasmid library was introduced into a parent $S$. cerevisiae strain, and the transformants were characterized and screened under stress conditions to identify the target of gene perturbation eliciting improved inhibitor resistance. The strain YC1 contains a multicopy plasmid with a yeast genomic DNA fragment insert (chrXV: 409,259-412,369). The insert harbors complete sequence of the gene WHI2, which encodes a cytoplasmatic globular scaffold protein required for activation of general stress response [64, 65]. Compared to the control strain S-C1 containing plasmid without the insert, the strain $\mathrm{YC} 1$ had significantly higher resistance to acetic acid [57]. The strain also showed significantly improved fermentation performance in corn stover hydrolysates compared to the control strain [57], suggesting its ability to resist mixed fermentation inhibitors. With the motivation to understand and compare transcriptional regulations under individual inhibitor stress versus mixed inhibitor stress in S. cerevisiae, we designed comparative transcriptomics experiments by focusing on two major inhibitors: acetic acid and furfural.

We characterized the strain and the wild-type control S-C1 in batch fermentation with the presence of acetic acid and/or furfural under oxygen-limited conditions (Fig. 1). The strain YC1 had significantly higher sugar consumption rates, ethanol productivities, and cell growth rates than the control $(t$ test, $P<0.05)$ under all the inhibitor conditions, including acetic acid alone, furfural alone, and acetic acid plus furfural (Fig. 1). The fermentation performances of $\mathrm{YC} 1$ and $\mathrm{S}-\mathrm{C} 1$ had no significant difference under the control condition without inhibitor (Additional file 1: Figure S2) suggesting that the improvement in the strain $\mathrm{YC} 1$ is associated with cellular response to inhibitor stress but not the ability in substrate utilization. It is worth mentioning that the 


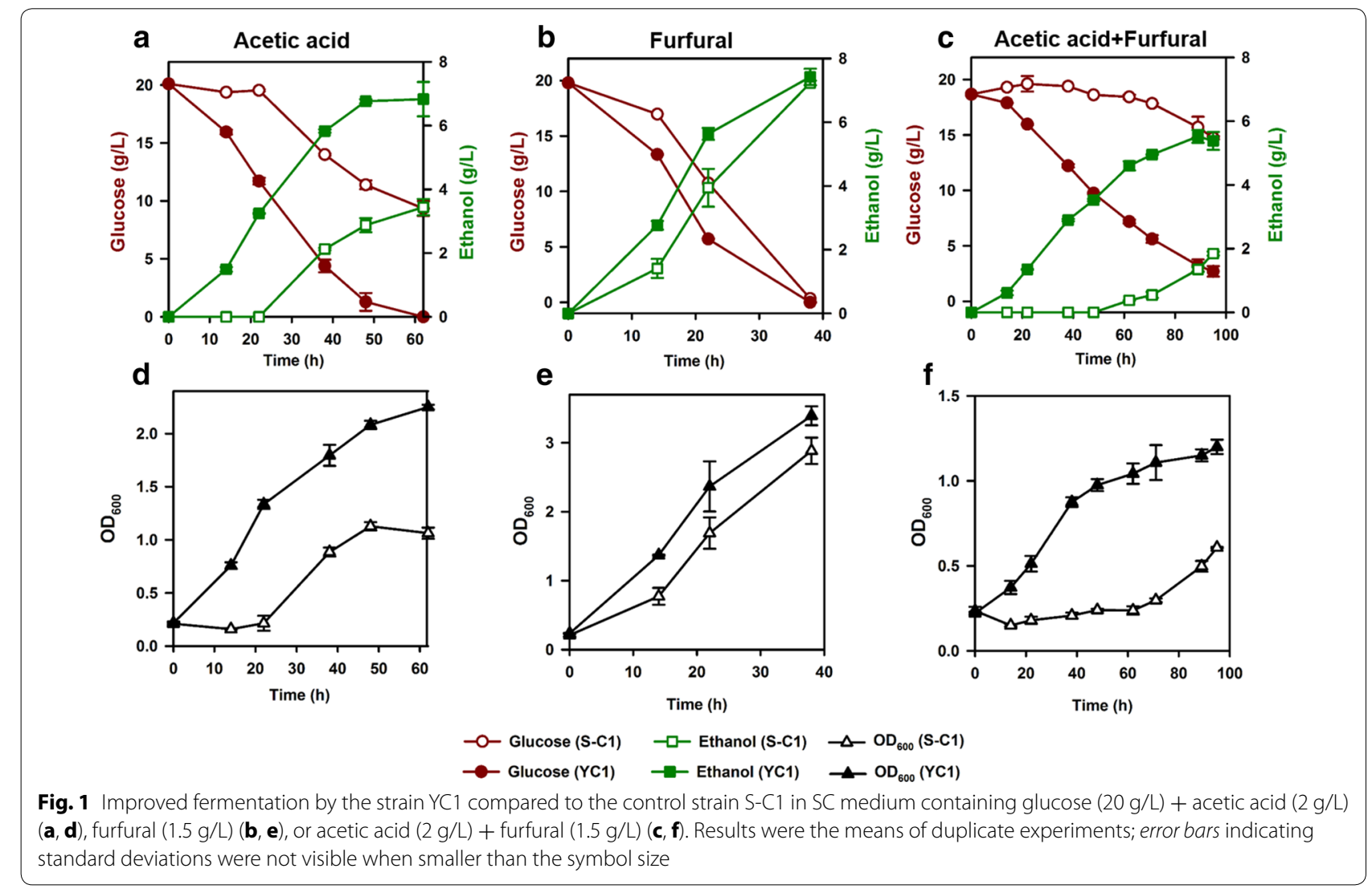

strain $\mathrm{YC} 1$ also demonstrated significant improvement in xylose fermentation under inhibitor stress as characterized previously [57]. The presence of both acetic acid and furfural severely inhibited glucose fermentation in the control strain (Fig. 1e) compared to the conditions with acetic acid or furfural alone (Fig. 1a, b). Noticeably, the strain YC1 showed substantially improved resistance to the mixed inhibitors as well as to single inhibitors. Specifically, the ethanol productivity of the strain $\mathrm{YC} 1$ was $400 \%$ higher than that of the control strain under acetic acid + furfural stress condition, while the enhancement was $270 \%$ for acetic acid stress condition and $170 \%$ for furfural stress condition. The results suggested that the strain YC1 had distinct inhibitor resistance mechanism compared to the wild-type strain $\mathrm{S}-\mathrm{C} 1$ in response to acetic acid and/or furfural stress. The improved sugar fermentation was also demonstrated in corn stover hydrolysates, where fermentation by the control strain was severely inhibited [57].

\section{The transcriptional responses of the wild-type strain to different stress conditions}

In order to reveal the mechanisms of the acetic acid and furfural tolerance of $S$. cerevisiae, the wild-type strain $\mathrm{S}-\mathrm{C} 1 \mathrm{has}$ been examined under 4 different conditions, i.e., without stress (Blank), with acetic acid (AA), furfural (FF), or acetic acid and furfural (AA\&FF). To systematically characterize the transcriptional responses of the strain $\mathrm{S}-\mathrm{C} 1$ to these different stress conditions, the RNAseq analysis was conducted correspondingly with three biological replicates. We then compared the gene expression profiles of the strain $\mathrm{S}-\mathrm{C} 1$ under each of the three stress conditions (AA, FF, and AA\&FF) to the control condition (Blank), respectively. From each of the comparisons, the transcripts would be identified as significantly up-/down- regulated by choosing the cut-off value (base mean $\geq 1000$; padj $\leq 0.001$ ) in DE-seq analysis package. The transcripts selected as differentially expressed were then used for gene ontology (GO) analysis.

In the control strain S-C1, 197 transcripts were identified to have different expression levels when growing with acetic acid, compared to those cultured under blank condition (Fig. 2 and Additional file 2: Table S1). Among them, 99 genes were up-regulated and 98 genes were down-regulated. Under furfural stress condition, 65 genes were identified to be differentially expressed, among which 20 genes were up-regulated and 45 genes were down-regulated. When the cells were cultured with both acetic acid and furfural, 192 genes had different expression levels, with 70 genes up-regulated and 

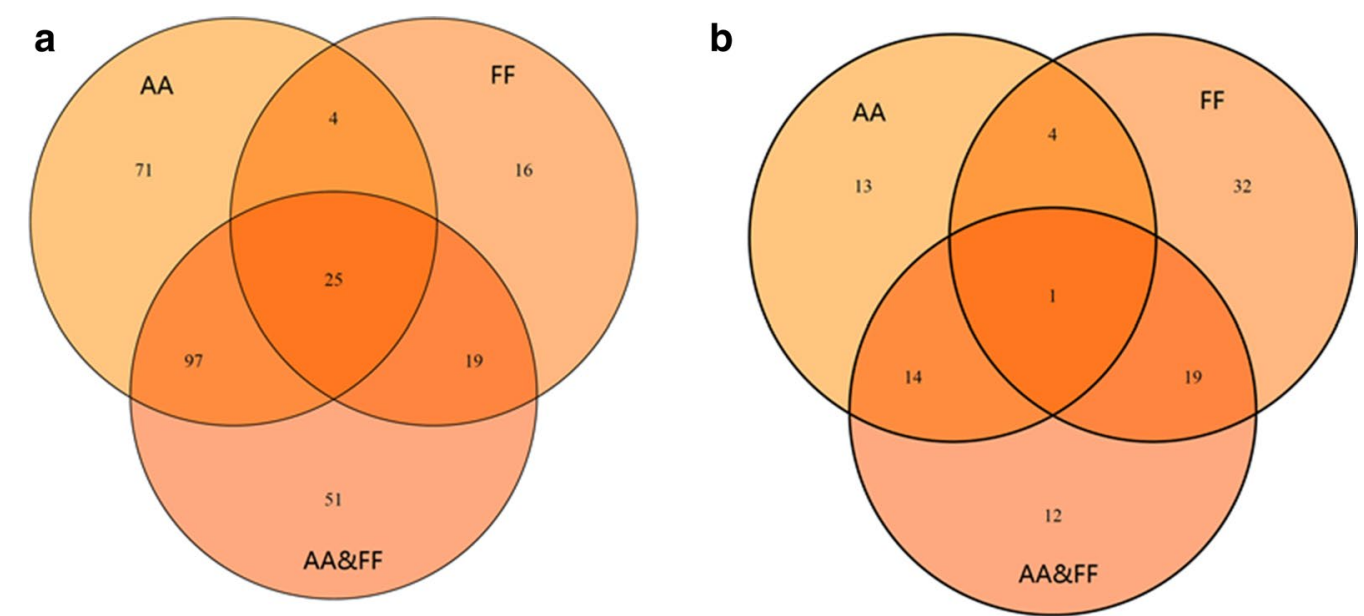

Fig. 2 Overlapping the differentially expressed genes in the control strain $\mathrm{S}-\mathrm{C} 1$ (a) and the strain $\mathrm{YC} 1$ (b) under different stress conditions. The gene expression profiles of growing without stress were used as the controls. AA growing with acetic acid; $F F$ growing with furfural; $A A \& F F$ growing with acetic acid and furfural

122 genes down-regulated. The transcriptome shifts in response to furfural and acetic acid in S. cerevisiae were also reported in previous studies [66].

Based on the GO analysis, several biological processes such as cellular amino acid metabolic process (GO:0006520), nucleobase-containing small molecule metabolic process (GO:0055086), and transmembrane transport (GO:0055085) were involved as the key responses to all of the stress conditions (Fig. 3). However, the importance of these bioprocesses to respond to different inhibitors in the wild-type $S$. cerevisiae varied from condition to condition, as reflected by the different percentages of the regulated genes involved in a specific bioprocess under different stress conditions (Fig. 3). For example, lipid metabolic processes (GO:0006629) showed its significant importance in acetic acid tolerance conditions, but only one gene related to lipid metabolic processes showed different expression levels under furfural tolerance conditions (Table 3). Also, the carbohydrate metabolic bioprocess (GO:0005975) and response to oxidative stress (GO:0006979) played more important roles in furfural tolerance than that in acetic acid tolerance. The cellular amino acids metabolic process (GO:0006520) was found to be key bioprocess in all the

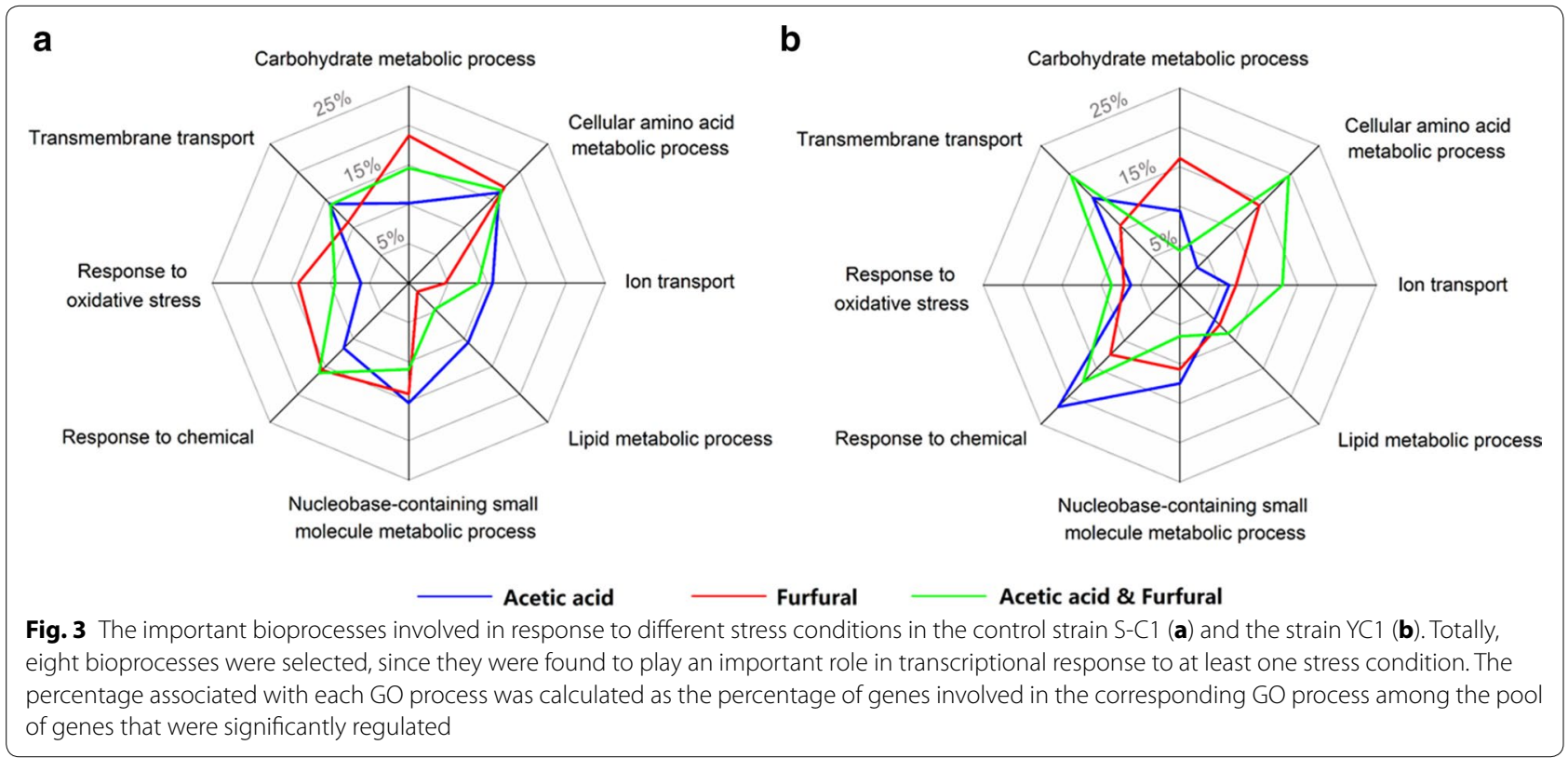




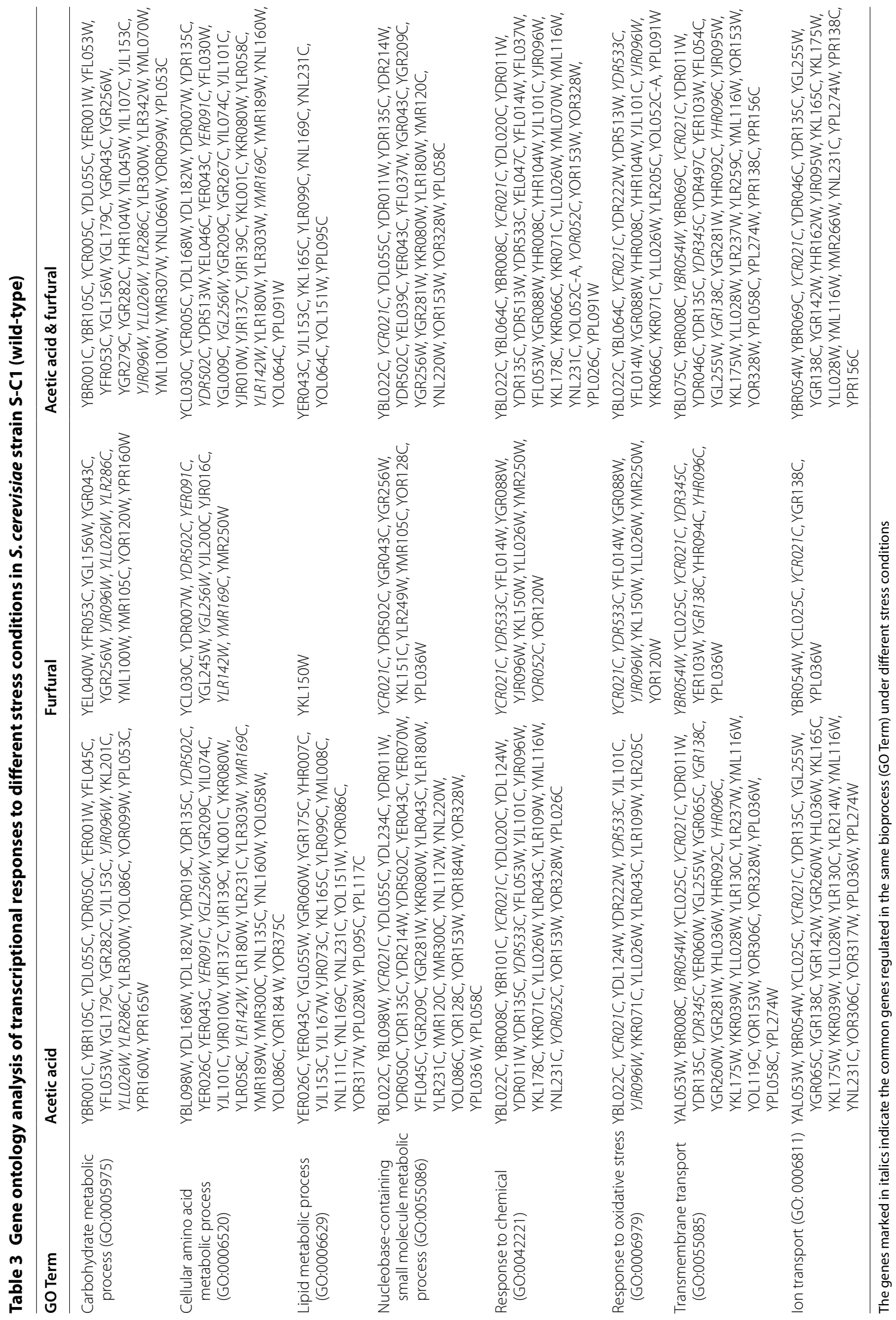


three stress conditions, though the specific genes related to the cellular amino acids metabolic process were not the same in response to different stress conditions. As shown in Table 3, only three genes in the cellular amino acids metabolic process were always regulated regardless of the stress condition, while 17 genes, 9 genes, and 25 genes were specifically regulated in response to the stress of acetic acid, furfural, acetic acid, and furfural, respectively. Overall, the data indicated that the strain $\mathrm{S}-\mathrm{C} 1$ adopted distinct endogenous genetic regulatory mechanisms to reprogram the cell metabolism in response to different stress conditions.

\section{The transcriptional responses of inhibitor-resistant strain to different stress conditions}

We next determined and compared the transcriptional responses of the inhibitor-resistant strain YC1 under different stress conditions. Basically, compared to the transcriptional profiles in the blank condition, 32 genes were identified to have different expression levels when YC1 was cultured under acetic acid stress condition, including 19 up-regulated genes and 13 down-regulated genes. Under furfural stress condition, 56 genes were identified to have different expression levels, with 40 genes up-regulated and 16 genes down-regulated. When the cells were cultured with both acetic acid and furfural, 46 genes showed different expression levels, among which 42 genes were all up-regulated and 4 genes were downregulated (Fig. 2 and Additional file 3: Table S2). It is interesting to notice that fewer genes were differentially expressed in $\mathrm{YC} 1$ compared to that in $\mathrm{S}-\mathrm{C} 1$, which could attribute to the activation of general stress responses by up-regulation of WHI2. It was found that Whi2 could interact with Msn2/Msn4 for full activation of gene expressions controlled by stress-responsive elements $[67,68]$. The key biological processes involved in stress response in the strain $\mathrm{YC} 1$ under different inhibitor stress conditions include cellular amino acid metabolic process (GO:0006520), nucleobase-containing small molecule metabolic process (GO:0055086), and transmembrane transport (GO:0055085) (Fig. 3). However, the gene targets that were subject to be regulated in each of the bioprocess were very different. In fact, no gene was universally regulated in all of the stress conditions (Table 4).

Notably, the impacts of different bioprocesses on resistance to stress conditions in the resistant strain $\mathrm{YC} 1$ were not the same as that in the strain S-C1 (Fig. 3). For example, the response to chemicals (GO:0042221) played a more important role in resistance to acetic acid in the strain YC1 (i.e., 7 genes involved in response to chemicals were differentially expressed in a pool of totally 32 genes that were differentially expressed) than in the control strain S-C1 (i.e., 23 genes were differentially expressed in a pool of totally 197 genes that were differentially expressed), while cellular amino acids metabolic process (GO:0006520) was more important in S-C1 (i.e., 32 genes were differentially expressed in a pool of totally 197 genes that were differentially expressed in $\mathrm{S}-\mathrm{C} 1$, while 1 gene was differentially expressed in a pool of totally 32 genes that were differentially expressed in YC1). Similarly, response to oxidative stress (GO:0006979) was a key biological process involved in transcriptional response to furfural in the strain S-C1, while its contribution to furfural resistance in the strain $\mathrm{YC} 1$ was relatively small (i.e., 9 genes were differentially expressed in a pool of totally 65 genes that were differentially expressed in S-C1, while 4 genes were differentially expressed in a pool of totally 56 genes that were differentially expressed in YC1). Under acetic acid and furfural mixed inhibitor condition, main biological processes for the stress responses in both strains included response to chemicals (GO:0042221), cellular amino acid metabolic process (GO:0006520), and transmembrane transport (GO:0055085). However, the impacts of these processes were not the same in the two strains; the transcriptional responses of the strain $\mathrm{YC} 1$ to mixed inhibitors were slightly more concentrated in cellular amino acid metabolic process and transmembrane transport compared to that of the strain S-C1. In general, 32 genes involved in cellular amino acid metabolic process were differentially expressed in a pool of totally 192 genes that were differentially expressed in S-C1, while 9 genes were differentially expressed in a pool of totally 46 genes that were differentially expressed in YC1. Also, 29 genes involved in transmembrane transport were differentially expressed in a pool of totally 192 genes that were differentially expressed in S-C1, while 9 genes were differentially expressed in a pool of totally 46 genes that were differentially expressed in YC1. These results indicated that the resistant strain $\mathrm{YC} 1$ had altered genetic regulatory networks and applied distinct molecular mechanisms (e.g., tuning the expression levels of genes involved in different biological pathways) from the wildtype strain to achieve improved stress response to acetic acid and/or furfural.

\section{The consensus transcriptional responses to different stress conditions}

In order to find the genetic traits leading to the enhanced resistance to different inhibitor stress conditions, we compared the gene expression profiles between the resistant strain YC1 and the control strain $\mathrm{S}-\mathrm{C} 1$ under each of the stress conditions. In general, 455 genes were identified to have different expression levels under the blank condition between the two yeast strains, while 536, 407, and 399 genes were identified to be differentially expressed in the strain YC1 when 


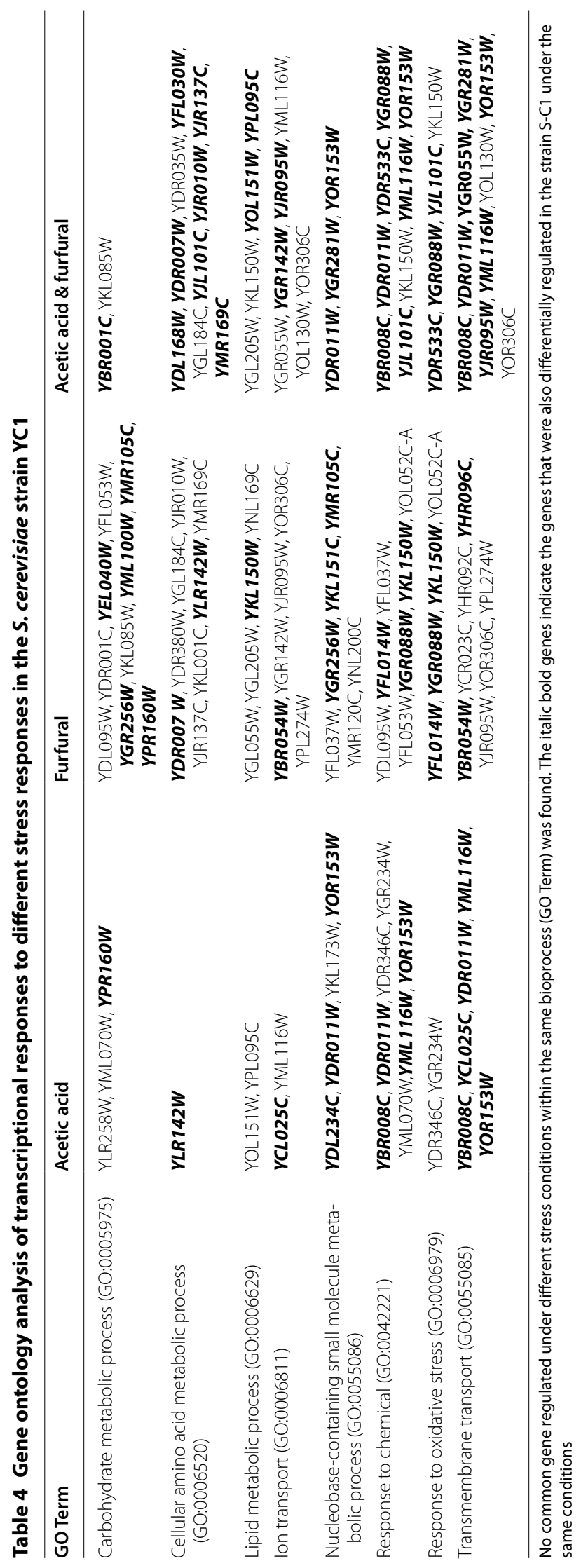


growing with acetic acid, furfural, acetic acid and furfural, respectively. We overlapped all of these differentially expressed genes and found 184 consensus genes that were always differentially regulated between the resistant strain YC1 and the control strain. Among the 184 consensus genes, 168 were found to be universally up-regulated in each of the stress condition, while 25 genes were universally down-regulated (Additional file 1: Figure S3, Additional file 4: Table S3). These consensus genes could most likely lead to the improved resistance to different stress conditions in the resistant strain YC1. Interestingly, we found one gene, YFL057C, demonstrated bifurcated behaviors in different stress conditions. The YFL057C gene expression was up-regulated under blank and furfural condition, but downregulated under acetic acid and acetic acid and furfural conditions. This indicated that the effects of regulating YFL057C expression could be contradictory for yeast resistance to acetic acid and furfural. The GO analysis for these consensus genes (Table 5) indicated several key biological processes involved, including carbohydrate metabolic process (GO: 0005975), response to chemical (GO: 0042221), transmembrane transport (GO: 0055085), cellular amino acid metabolic process (GO: 0006520), and nucleobase-containing small molecule metabolic process (GO: 0055086).

Since the exhibition of complex genetic responses of $S$. cerevisiae to the environment was largely due to the transcription factors (TFs) that control the flow of genetic information from DNA to mRNA, we next applied a TF analysis to identify the TFs evolved in regulating the consensus genes using the YEASTRACT database. The percentage of genes a TF can regulate was defined as the ratio of the number of consensus genes the TF can regulate to the number of total consensus genes. We then generated a TF profile by choosing the top 20 candidates based on the coverage of genes they regulated (Fig. 4). Among the top four TF candidates, three of them (Ace2p, Sfp1p, and Ste12p) participate in regulating the life cycle and carbon metabolism of the yeast, while one TF (Msn2p) was found to involve in chemical responses. The most important TFs identified were Ace2p and Sfp1p, which were ranked as the top 1 and $2 \mathrm{TFs}$ that are involved in regulating yeast response to acetic acid and furfural stress. Ace2p encodes a transcription factor that belongs to the $\mathrm{C} 2 \mathrm{H} 2$ zinc finger class [69]. At the end of mitosis, Ace2p acts specifically in daughter cells to activate transcription of genes such as chitinases and glucanases that are required to destroy the septum and allow mother and daughter cells to separate after budding [69]. Sfp1p regulates the expression of nearly $10 \%$ of yeast genes, most of which are involved in ribosome biogenesis and the regulation of cell size. Under optimal growth conditions, Sfp1p is localized to the nucleus and helps promote ribosome protein (RP) gene expression by binding to the promoters of RP genes [70]. When cells suffered nutrient limitation or chemical stress, Sfp1p is released from RP gene promoters and leaves the nucleus. Sfp1p mediates the information from stress-responsive signaling pathways to the regulation of RP gene expression and then finally bridges the physiological changes corresponding to the environment.

Table 5 Gene ontology analysis of the consensus transcriptional responses by comparing gene expression profiles of the inhibitor-resistant strain YC1 and the wild-type strain S-C1 across different stress conditions

\begin{tabular}{|c|c|}
\hline GO term (GO ID) & Genes Annotated to the GO term \\
\hline Carbohydrate metabolic process (GO:0005975) & $\begin{array}{l}\text { YBR001C, YBR105C, YCL018W, YCL040W, YCR005C, YDL174C, YDL193W, } \\
\text { YER062C, YFL053W, YGL134W, YGR254W, YHR046C, YHR174W, YJR096W, } \\
\text { YKL201C, YLL026W, YML100W, YMR135C, YMR145C, YNR001C, YOL032W, } \\
\text { YOL059W, YOL086C, YOL136C, YOR299W }\end{array}$ \\
\hline Response to chemical (GO:0042221) & $\begin{array}{l}\text { YBR006W, YBR101C, YCR021C, YDL124W, YDR135C, YFL053W, YFR022W, } \\
\text { YGR008C, YJL034W, YJL128C, YJR096W, YKL062W, YKL073W, YKL109W, } \\
\text { YKR066C, YKR071C, YLL026W, YLR350W, YMR250W, YNL007C, YOL081W, } \\
\text { YPL026C, YPL239W, YPR036W-A }\end{array}$ \\
\hline Transmembrane transport (GO:0055085) & $\begin{array}{l}\text { YAL005C, YBR287W, YCL025C, YCR021C, YCR023C, YDR046C, YDR086C, } \\
\text { YDR135C, YDR345C, YEL024W, YER103W, YGL006W, YGR065C, YGR138C, } \\
\text { YHL036W, YHR092C, YJL034W, YKL073W, YKL174C, YLL024C, YNL125C, } \\
\text { YPL036W, YPR156C }\end{array}$ \\
\hline Cellular amino acid metabolic process (GO:0006520) & $\begin{array}{l}\text { YBR006W, YCL018W, YCR005C, YDL182W, YDR135C, YGL196W, YIR034C, } \\
\text { YJR078W, YJR103W, YJR109C, YJR137C, YLR142W, YMR250W, YNL037C, } \\
\text { YNL073W, YNR001C, YOL086C, YOR136W, YOR202W, YPL160W, YPR035W }\end{array}$ \\
\hline Nucleobase-containing small molecule metabolic process (GO:0055086) & $\begin{array}{l}\text { YCR021C, YDR135C, YDR529C, YEL021W, YEL024W, YEL041W, YER036C, } \\
\text { YER037W, YJR078W, YJR103W, YKL073W, YMR145C, YNL088W, YNL220W, } \\
\text { YOL059W, YOL081W, YOL086C, YOR204W, YPL036W, YPR181C }\end{array}$ \\
\hline
\end{tabular}




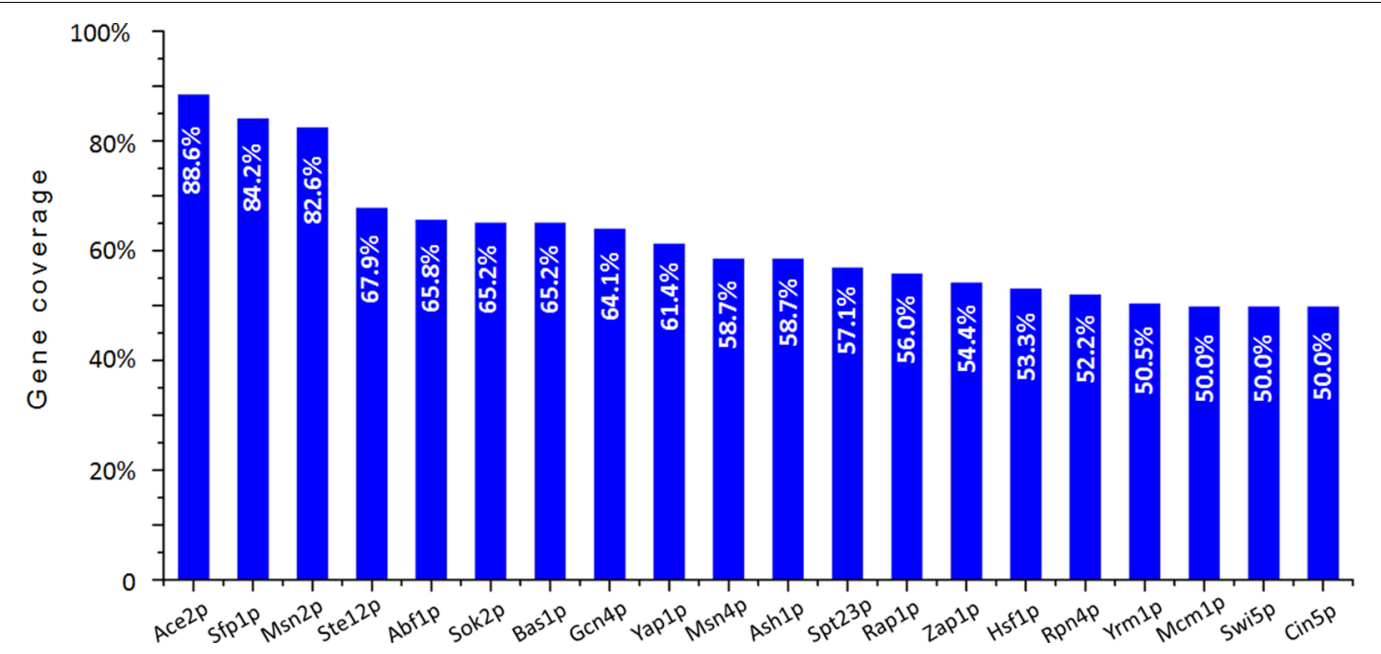

Fig. 4 Transcription factor (TF) profiles for regulating the consensus genes involved in response to different stress conditions. The percentage of genes regulated by each of the top 20 TFs was calculated as the number of genes regulated by the TF relative to the total number of consensus genes involved in response to different stress conditions

\section{Effects of overexpressing ACE2 or SFP1 on resistance to acetic acid and furfural}

Since the TFs identified through the TF analysis are involved in regulating consensus genes related to stress response to acetic and furfural in S. cerevisiae, we hypothesized that the inhibitor resistance phenotype could be possibly altered when the relevant TFs are perturbed. We chose the top two TFs Ace2p and Sfp1p and evaluated the effects of their overexpression on inhibitor resistance in $S$. cerevisiae. Two engineered yeast strains were constructed by overexpressing the ACE2 gene or SFP1 gene in the parent strain SR8-trp, respectively, yielding two new strains $S$-ACE2 and $S$-SFP1 (Table 1). Performances of the strains $S$-ACE2, S-SFP1 and the control $S-C 1$ in glucose fermentation under three different inhibitor stress conditions (acetic acid alone, furfural alone, and acetic acid + furfural) were compared (Fig. 5). Overall, overexpression of $A C E 2$ or SFP1 resulted in significant increase in specific sugar consumption rates, ethanol productivities, and cell growth rates in the engineered strains compared to the control under different inhibitor conditions $(t$ test, $P<0.05)$. In fermentation with the presence of acetic acid and furfural, overexpression of SFP1 improved specific ethanol productivity by nearly four times, while overexpression of $A C E 2$ enhanced the rate by three times. The positive effects of overexpressing SFP1 or ACE2 were also determined in another wild-type strain, S. cerevisiae CEN.PK. Specific cell growth rates in the presence of acetic acid $(2.5 \mathrm{~g} / \mathrm{L})+$ furfural $(1.5 \mathrm{~g} / \mathrm{L})$ stress were enhanced by $25 \%$ (for SFP1 overexpressing strain) and $18 \%$ (for $A C E 2$ overexpressing strain) compared to the wild-type control containing backbone plasmid. Additionally, we compared the effects of Sfp1p and Ace $2 p$ to Haalp in terms of acetic acid resistance, since Haa1p is a well-known transcription factor regulating yeast stress response to acetic acid [44, 45]. Strains overexpression of SFP1 or ACE2 had improved specific sugar consumption rate similar to the strain overexpressing $H A A 1$, while $H A A 1$ overexpression elicited better cell growth under acetic acid stress (Additional file 1: Figure S4). The results suggest that the perturbation of the transcription factor Sfp1p or Ace2p could elicit alteration of genetic regulatory networks which provided protection effects against acetic acid and furfural stress in $S$. cerevisiae.

In addition, since overexpression of SFP1 had substantial effect in improving resistance to acetic acid and furfural mixture in the wild-type yeast strain, we further evaluated the effect of overexpressing SFP1 together with WHI2 (overexpression of which improved inhibitor resistance in the resistant strain $\mathrm{YC} 1$ ). A new group of engineered strains were constructed, including S-WHI2SPF1, S-WHI2-c, and S-C2 (Table 1), and their fermentation performances in medium containing glucose and toxic levels of acetic acid and furfural were quantified and compared (Fig. 6). The strain S-WHI2-SPF1 had the highest sugar consumption rate, ethanol productivity and cell growth rate, while the control strain only consumed less than $5 \mathrm{~g} / \mathrm{L}$ glucose within the experimental time frame. Compared to the strain S-WHI2 which overexpressed only WHI2, the strain S-WHI2-SPF1 had $42 \%$ increase in ethanol productivity and $20 \%$ increase in cell growth rate, suggesting the positive effect of Sfp1p in optimizing yeast resistance to mixed fermentation inhibitors. These 


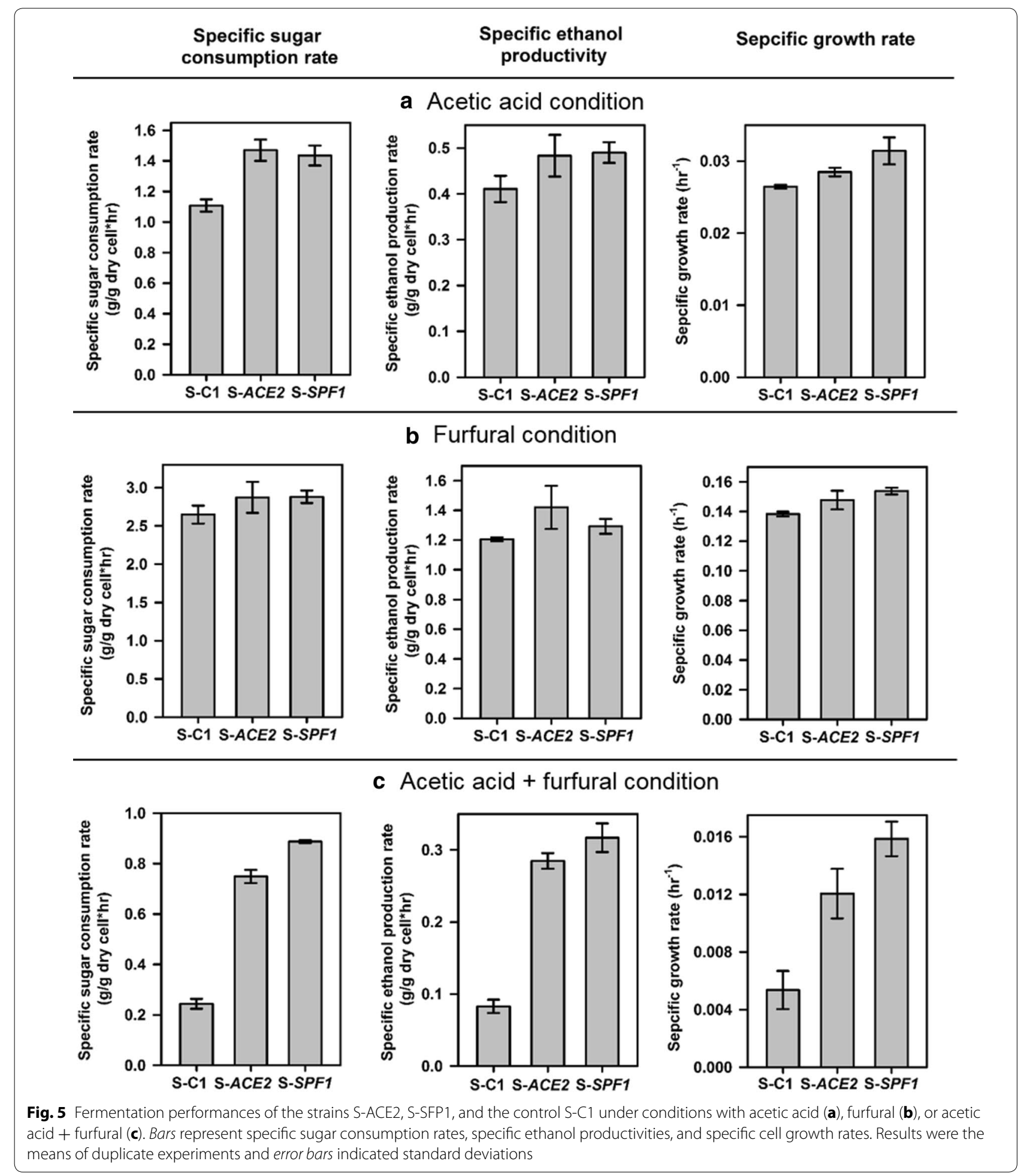

experimental data on the effects of Sfp1p and Ace2p indicated that the transcriptomic and bioinformatics analysis presented in this study could be a promising method framework to discover relevant TFs as genetic perturbation targets to optimize the complex phenotype such as mixed inhibitor resistance in S. cerevisiae. 


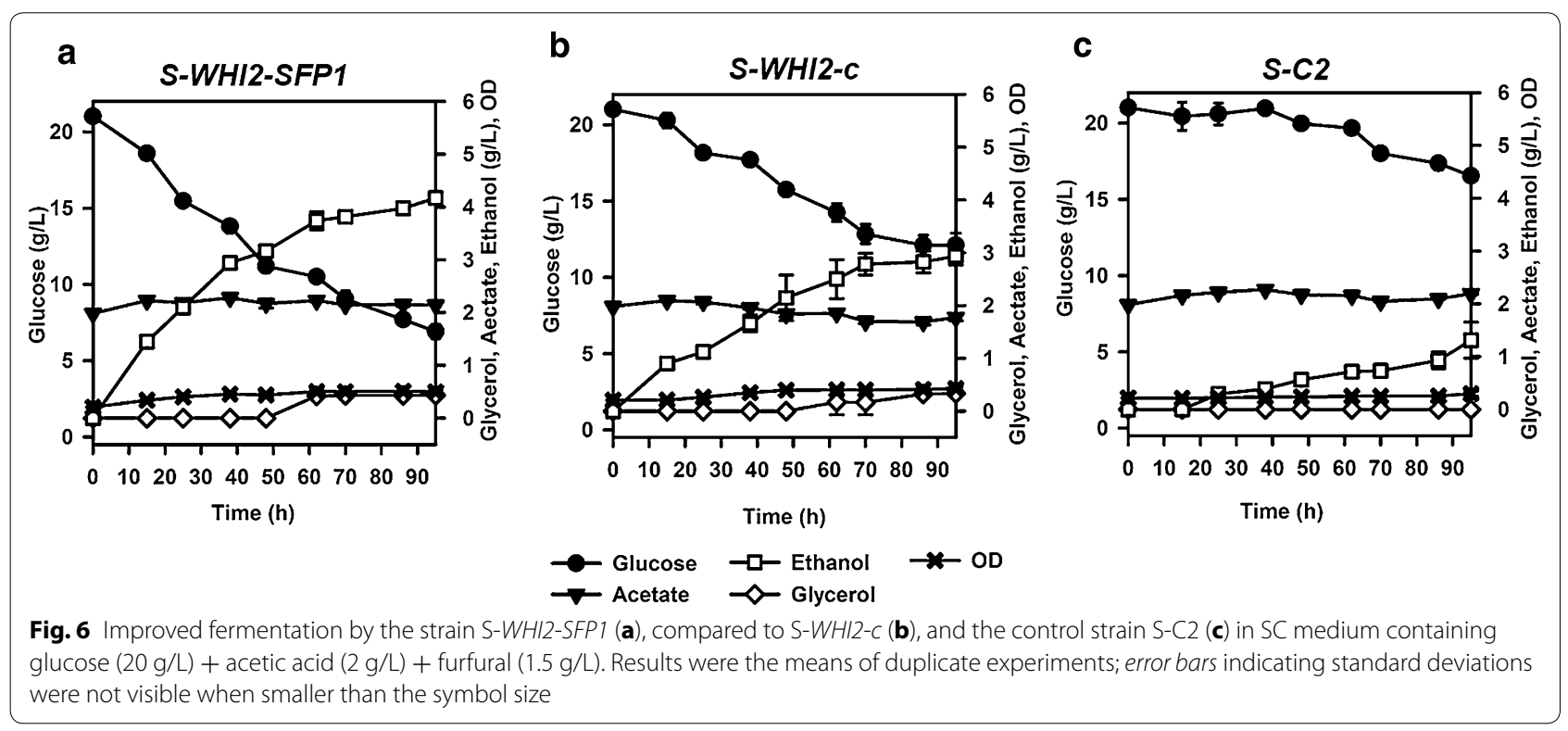

\section{Discussion}

In this study, the transcriptional responses of $S$. cerevisiae to fermentation inhibitor stress conditions once again confirmed that no single pathway could be found to be exclusively responsible for the resistance phenotype. Rather, global gene expressions need to be rewired to respond to the stress conditions. It is interesting to notice that the transcriptional profiles varied in response to acetic acid and furfural, which could be related to the different toxic effects of acetic acid and furfural. In general, we found that the transmembrane transport processes play pivotal roles in both resistant strain $\mathrm{YC} 1$ and the wild-type strain in response to acetic acid, while the carbohydrate metabolic process is crucial for stress response to furfural. Additionally, the distinct transcriptional responses to acetic acid and furfural mixture of the resistant strain versus the wildtype suggested the importance of biological processes such as transmembrane transport, cellular amino acid metabolic process, and response to chemical in regulating yeast resistance to the mixed fermentation inhibitors.

Transcription factor analysis of consensus genes that were up- or down- regulated under all of the stress conditions and blank condition in the strain $\mathrm{YC} 1$ versus wild-type revealed key determinants for improved yeast resistance to acetic acid and furfural. It should be noted that some differentially expressed genes from RNA-seq dataset could be just passively up- or down- regulated and may not contribute to eliciting stress responses. In order to remove the false-positives and narrow down our genetic targets related to improving the inhibitor resistance phenotype, we screened for the consensus genes across all of the cultivation conditions, followed by grouping the consensus genes by TFs that were most likely to regulate them. Among the top TFs (gene coverage above $80 \%$ ), Sfp1p emerges intensively as the transcriptional regulation of ribosomal genes in response to nutrient starvation and stress [43]. Although there is no direct evidence that whether or not Sfp1p could participate in the control of the genome-wide transcriptional response to the weak acids, it has been reported that all the molecules which could induce general nutrient limitation were also suggested to have a pro-oxidant effect in yeast cells [43], which could explain why Sfp1p stood out as an important TF in this study, since both of acetic acid and furfural have the oxidative properties inside S. cerevisiae. Another dominant TF, Ace2p, could activate several genes with critical roles in cell separation and control daughter cell-specific gene expression [71], which could possibly contribute to releasing the inhibition of growth rate and cell-cycle changes of $S$. cerevisiae induced by chemicals in this study. Interestingly, as discovered previously in studying stress responses of S. cerevisiae to HMF and furfural in xylose utilization [72], Ace2p was found to be a reporter transcription factor of the genes downregulated after pulsing of HMF and furfural in the xylose consumption phase. This indicated a bifurcated role Ace2 could play in regulating yeast metabolism to resist different inhibitors (acetate + furfural v.s. HMF + furfural) under different sugar utilization conditions (e.g., glucose metabolism v.s. xylose metabolism).

While not tested in this study, appropriate perturbation of other top ranked TFs such as Msn2p, Msn4p, Gcn4p, Yap1p, Hsf1p, Rpn4p, and Cin5p could potentially generate beneficial genetic traits to improve yeast stress 
responses, since these TFs are heavily involved in regulating stress-responsive genes in yeast to resist various stress factors. For example, the participation of Msn2p in the transcriptional response to fermentation inhibitors has been documented before [42-44]. Initial characterization of the effects of overexpressing MSN2 in the strain SR8-trp showed improved specific cell growth rate by $7 \%$ compared to that of S-C1 under furfural $(1.5 \mathrm{~g} / \mathrm{L})$ stress in synthetic complete medium, but no significant improvement was observed under acetic acid $(2 \mathrm{~g} / \mathrm{L})$ stress in the experimental condition, indicating the distinct regulatory mechanism for different fermentation inhibitors. Also, the transcription factor Yap1p has been discovered previously to contribute to inhibitor tolerance in engineered S. cerevisiae for fermenting lignocellulosic hydrolysate [73].

This study not only identified alteration of genetic regulatory networks and related TFs through computational bioinformatics analysis, but also experimentally determined the effect of top TFs as overexpression targets in enhancing mixed inhibitor resistance in the S. cerevisiae strains tested in this study. The improvement brought by overexpression SFP1 and ACE2 (Figs. 5, 6) suggested that our approach was effective to identify transcription factor targets relevant to optimizing the target phenotype (i.e., resistance to acetic acid and furfural). Co-expressing $A C E 2$ and SFP1 also significantly improved yeast resistance to acetic acid and furfural mixture compared to expressing $A C E 2$ or SFP1 individually, evidenced by the enhanced specific cell growth rate (by $31 \%, P<0.05$ ) and glucose consumption rate (by $19 \%, P<0.05$ ), indicating there could be some synergistic effects from combined perturbation of the two TFs. On-going work is focused on characterizing the effects of the identified TFs in more detail and elucidating their functions in yeast mixed inhibitor resistance.

It should be noted that it is intrinsically complex and challenging to engineer yeast resistance to mixed fermentation inhibitors because each type of inhibitor may have distinct toxic effects and cellular stress response mechanisms $[9,10]$. Our work here illustrated a novel omics-guided metabolic engineering framework where transcription factors underlying a desirable complex phenotype could be identified and perturbed for strain optimization. Specifically, the frame work includes two key components. On one hand, comparative transcriptomic analysis generates information that will be used to uncover the underlying regulatory mechanisms for the desired phenotype (e.g., inhibitor resistance) and determine key TFs involved. On the other hand, since the identified TFs regulate the genes associated with target phenotype, the TFs will serve as the promising genetic perturbation targets in metabolic engineering to improve the phenotype of interest and achieve strain optimization. While the present study conducted overexpression of the selected TFs as the initial demonstration, other perturbation strategy could also be applied such as deletion, screening of TF mutant library, and fine-tuning to determine the best possible strategy for phenotype improvement. Additionally, as the strain YC1 contains xylose-utilizing pathway, future study will determine the effects of genetic perturbation on improving fermentation of glucose and xylose (the two most abundant sugars from lignocellulosic biomass) in the presence of mixed fermentation inhibitors. Transcriptional regulatory networks could vary in xylose fermentation versus glucose fermentation in S. cerevisiae $[74,75]$, so it would be meaningful to investigate inhibitor stress response mechanisms and identify transcription factor targets eliciting improved inhibitor resistance in both sugar fermentation conditions.

Overall, in this proof-of-concept study, we confirmed the pivotal role played by TFs in stress response and demonstrated that the yeast resistance to stress factors could indeed be improved by perturbing the key TFs. Future work will systemically evaluate all the other highly ranked TFs and identify their effects on yeast stress responses to mixed fermentation inhibitors. Besides, while the present study demonstrated successful identification of novel TFs for improved yeast resistance to acetic acid and furfural, it would be meaningful to determine molecular basis and genetic targets for tolerance to phenolic compounds as well. Engineering microbial resistance to fermentation inhibitors becomes even more challenging and complex as the types of inhibitors expanded in the mixture. With the transcriptomicguided metabolic engineering approach demonstrated in the present work, our future work will apply the method to identify new TF targets, as well as further characterize the TFs already identified in this study, for their functions in eliciting improved resistance to all the three inhibitors.

\section{Conclusions}

In this study, we applied comparative transcriptomics analysis to advance understanding of the molecular basis for stress responses of $S$. cerevisiae to both single and mixed fermentation inhibitors of acetic acid and furfural. We identified two transcription factors, Sfp1p and Ace2p, as the pivotal regulators in S. cerevisiae to control the yeast resistance to acetic acid and furfural, and confirmed their positive effects on improving the inhibitor resistance via gene overexpression. To our best knowledge, it is the first time these two transcription factors were uncovered for their functions in improving yeast resistance to mixed fermentation inhibitors. The transcriptomic-guided metabolic engineering approach we demonstrated in this study could be potentially used as a strategy to improve complex phenotypes of industrial microorganisms. 


\section{Additional files}

Additional file 1: Figure S1. Correlation of qPCR results and RNAseq analysis of gene expressions $(R 2=0.99)$. Figure S2. Fermentation performance of the strain YC1 and the control strain S-C1 in SC medium containing glucose $(20 \mathrm{~g} / \mathrm{L})$ without acetic acid. Results were the means of duplicate experiments. Deviations are less than $10 \%$. Figure S3. Overlapping the differentially expressed genes by comparing the transcriptional profiles of the control strain S-C1 and the strain YC1 under different stress conditions. Blank: growing without stress; AA: growing with acetic acid; FF: growing with furfural; AA\&FF: growing with acetic acid and furfural. Figure S4. Fermentation performances of the strains S-HAA1, S-ACE2, S-SFP1 and the control S-C1 under conditions with acetic acid. Bars represent specific sugar consumption rates and specific cell growth rates. Results were the means of duplicate experiments. Deviations are less than $15 \%$.

Additional file 2: Table S1. Transcriptional analysis and GO analysis of the wild-type strain to different stress conditions.

Additional file 3: Table S2. Transcriptional analysis and GO analysis of the inhibitor-resistant strain to different stress conditions.

Additional file 4: Table S3. Transcriptional analysis and GO analysis of consensus genes.

\section{Abbreviations}

HMF: 5-hydroxymethylfurfural; RNA-seq: ribonucleic acid (RNA) sequencing; TFs: transcription factors; YP: yeast extract-peptone; SC: synthetic complete; PCR: polymerase chain reaction; qPCR: quantitative polymerase chain reaction; AA: acetic acid; FF: furfural; AA\&FF: acetic acid and furfural; GO: gene ontology; RP: ribosome protein.

\section{Authors' contributions}

$Y C, X F$, and NW designed experiments. YC developed the resistant strain and performed gene perturbation for strain engineering. JYS, XF, and NW performed RNA-seq data analysis. YC, JYS, and JS performed fermentation experiments. YC and TJ prepared and purified RNA. YC, JYS, XF, and NW analyzed and wrote the manuscript. All authors read and approved the final manuscript.

\section{Author details}

${ }^{1}$ Department of Civil and Environmental Engineering and Earth Sciences, University of Notre Dame, 106E Cushing Hall of Engineering, Notre Dame, South Bend, IN 46556, USA. ${ }^{2}$ Department of Biological Systems Engineering, Virginia Polytechnic Institute and State University, Blacksburg, VA, USA. ${ }^{3}$ Department of Civil and Environmental Engineering, University of Pittsburgh, Pittsburgh, PA, USA.

\section{Acknowledgements}

We thank Dr. Yong-Su Jin for providing the strains SR8-trp and SR8-4. We thank Dr. Saikumar Karyala and Dr. Robert Settlage in Genomics Research Laboratory at Virginia Bioinformatics Institute, Virginia Tech for performing the RNA-seq analysis and bioinformatics analysis.

\section{Competing interests}

The authors declare that they have no competing interests.

Received: 9 September 2015 Accepted: 15 December 2015

Published online: 13 January 2016

\section{References}

1. Hahn-Hägerdal B, Galbe M, Gorwa-Grauslund MF, Lidén G, Zacchi G. Bio-ethanol - the fuel of tomorrow from the residues of today. Trends Biotechnol. 2006;24:549-56.

2. Tilman D, Socolow R, Foley JA, Hill J, Larson E, Lynd L, Pacala S, Reilly J, Searchinger T, Somerville C, Williams R. Beneficial biofuels-the food, energy, and environment trilemma. Science. 2009;325:270-1.
3. Lynd LR, van Zyl WH, McBride JE, Laser M. Consolidated bioprocessing of cellulosic biomass: an update. Curr Opin Biotechnol. 2005;16:577-83.

4. Somerville C, Youngs H, Taylor C, Davis SC, Long SP. Feedstocks for lignocellulosic biofuels. Science. 2008:329:790-2.

5. Lu Y, Warner R, Sedlak M, Ho N, Mosier NS. Comparison of glucose/xylose cofermentation of poplar hydrolysates processed by different pretreatment technologies. Biotechnol Prog. 2009;25:349-56.

6. Olsson L, Hähn-Hagerdal B. Fermentative performance of bacteria and yeasts in lignocellulose hydrolysates. Process Biochem. 1993;28:249-57.

7. Klinke HB, Thomsen AB, Ahring BK. Inhibition of ethanol-producing yeast and bacteria by degradation products produced during pre-treatment of biomass. Appl Microbiol Biotechnol. 2004;66:10-26.

8. Almeida JRM, Modig T, Petersson A, Hahn-Hägerdal B, Lidén G, GorwaGrauslund MF. Increased tolerance and conversion of inhibitors in lignocellulosic hydrolysates by Saccharomyces cerevisiae. J Chem Technol Biotechnol. 2007:82:340-9.

9. Jonsson LJ, Alriksson B, Nilvebrant NO. Bioconversion of lignocellulose: inhibitors and detoxification. Biotechnol Biofuels. 2013;6:16-25.

10. Palmqvist $E_{,}$Hahn-Hägerdal B. Fermentation of lignocellulosic hydrolysates. II: inhibitors and mechanisms of inhibition. Bioresour Technol. 2000;74:25.

11. Carroll A, Somerville C. Cellulosic biofuels. Annu Rev Plant Biol. 2009;60:165-82

12. Scheller HV, Ulvskov P. Hemicelluloses. Annu Rev Plant Biol. 2010;61:263-89.

13. Palmqvist $E_{,}$Hahn-Hägerdal B. Fermentation of lignocellulosic hydrolysates. I: inhibition and detoxification. Bioresour Technol. 2000;74:17-24.

14. García-Aparicio MP, Ballesteros I, González A, Oliva JM, Ballesteros M, Negro MJ. Effect of inhibitors released during steam-explosion pretreatment of barley straw on enzymatic hydrolysis. Appl Biochem Biotechnol. 2006;278:129-32

15. Martin C, Alriksson B, Sjöde A, Nilvebrant NO, Jönsson LJ. Dilute sulfuric acid pretreatment of agricultural and agro-industrial residues for ethanol production. Appl Biochem Biotechnol. 2007;137:339-52.

16. Schmidt AS, Thomsen AB. Optimization of wet oxidation pretreatment of wheat straw. Bioresour Technol. 1998;64:139-51.

17. Fang Z. Pretreatment techniques for biofuels and biorefineries. Berlin: Springer; 2013.

18. Tengborg C, Galbe M, Zacchi G. Reduced inhibition of enzymatic hydrolysis of steam-pretreated softwood. Enzyme Microb Technol. 2001;28:835-44.

19. Hong KK, Nielsen J. Metabolic engineering of Saccharomyces cerevisiae: a key cell factory platform for future biorefineries. Cell Mol Life Sci. 2012;69:2671-90.

20. Krivoruchko A, Siewers V, Nielsen J. Opportunities for yeast metabolic engineering: lessons from synthetic biology. Biotechnol J. 2011;6:262-76.

21. Pampulha ME, Loureiro-Dias MC. Combined effect of acetic acid, $\mathrm{pH}$ and ethanol on intracellular $\mathrm{pH}$ of fermenting yeast. Appl Microbiol Biotechnol. 1989;31:547-50

22. Piper P, Calderon CO, Hatzixanthis K, Mollapour M. Weak acid adaptation: the stress response that confers yeasts with resistance to organic acid food preservatives. Microbiology. 2001;147:2635-46.

23. Verduyn C, Postma E, Scheffers WA, Van Dijken JP. Effect of benzoic acid on metabolic fluxes in yeasts: a continuous-culture study on the regulation of respiration and alcoholic fermentation. Yeast. 1992;8:501-17.

24. Eraso P, Gancedo C. Activation of yeast plasma membrane ATPase by acid pH during growth. FEBS Lett. 1987;224:187-92.

25. Russell JB. Another explanation for the toxicity of fermentation acids at low pH-anion accumulation versus uncoupling. J Appl Bacteriol. 1992;73:363-70.

26. Casal M, Cardoso H, Leao C. Mechanisms regulating the transport of acetic acid in Saccharomyces cerevisiae. Microbiology. 1996;142:1385-95.

27. Modig T, Liden G, Taherzadeh MJ. Inhibition effects of furfural on alcohol dehydrogenase, aldehyde dehydrogenase and pyruvate dehydrogenase. Biochem J. 2002:363:769-76.

28. Palmqvist E, Almeida JS, Hahn-Hägerdal B. Influence of furfural on anaerobic glycolytic kinetics of Saccharomyces cerevisiae in batch culture. Biotechnol Bioeng. 1999;62:447-54.

29. Taherzadeh MJ, Gustafsson L, Niklasson C, Liden G. Physiological effects of 5-hydroxymethylfurfural on Saccharomyces cerevisiae. Appl Microbiol Biotechnol. 2000;53:701-8. 
30. Horvath IS, Franzen CJ, Taherzadeh MJ, Niklasson C, Lidén G. Effects of furfural on the respiratory metabolism of Saccharomyces cerevisiae in glucose-limited chemostats. Appl Environ Microbiol. 2003;69:4076-86.

31. Taherzadeh MJ, Gustafsson L, Niklasson C, Lidén G. Conversion of furfural in aerobic and anaerobic batch fermentation of glucose by Saccharomyces cerevisiae. J Biosci Bioeng. 1999;87:169-74.

32. Diaz De Villegas ME, Villa P, Guerra M, Rodriguez E, Redondo D, Martinez A, Conversion of furfural into furfuryl alcohol by Saccharomyces cervisiae 354. Acta Biotechnol. 1992;12:351-4.

33. Mussatto SI, Roberto IC. Alternatives for detoxification of diluted-acid lignocellulosic hydrolyzates for use in fermentative processes: a review. Bioresour Technol. 2004;93:1-10.

34. Ling H, Teo W, Chen B, Leong SSJ, Chang MW. Microbial tolerance engineering toward biochemical production: from lignocellulose to products. Curr Opin Biotechnol. 2014;29:99-106.

35. Petersson A, Almeida JRM, Modig T, Karhumaa K, Hahn-Hägerdal B, Gorwa-Grauslund MF, Lidén G. A 5-hydroxymethyl furfural reducing enzyme encoded by the Saccharomyces cerevisiae ADH6 gene conveys HMF tolerance. Yeast. 2006;23:455-64.

36. Liu ZL, Moon J. A novel NADPH-dependent aldehyde reductase gene from Saccharomyces cerevisiae NRRL Y-12632 involved in the detoxification of aldehyde inhibitors derived from lignocellulosic biomass conversion. Gene. 2009;446:1-10.

37. Kim SK, Jin YS, Choi IG, Park YC, Seo JH. Enhanced tolerance of Saccharomyces cerevisiae to multiple lignocellulose-derived inhibitors through modulation of spermidine contents. Metab Eng. 2015;29:46-55.

38. Gorsich SW, Dien BS, Nichols NN, Slininger PJ, Liu ZL, Skory CD. Tolerance to furfural-induced stress is associated with pentose phosphate pathway genes ZWF1, GND1, RPE1, and TKL1 in Saccharomyces cerevisiae. Appl Microbiol Biotechnol. 2006;71:339-49.

39. Hasunuma T, Ismail KSK, Nambu Y, Kondo A. Co-expression of TAL and $A D H 1$ in recombinant xylose-fermenting Saccharomyces cerevisiae improves ethanol production from lignocellulosic hydrolysates in the presence of furfural. J Biosci Bioeng. 2014;117:165-76.

40. Kim SR, Skerker JM, Kang W, Lesmana AL, Wei N, Arkin AP, Jin YS. Rational and evolutionary engineering approaches uncover a small set of genetic changes efficient for rapid xylose fermentation in Saccharomyces cerevisiae. PLoS One. 2013;8:e57048.

41. dos Santos S, Sá-Correia I. Genome-wide identification of genes required for yeast growth under imatinib stress: vacuolar $\mathrm{H}^{+}$-ATPase function is an important target of this anticancer drug. OMICS. 2009;13:185-98.

42. Mira NP, Palma M, Guerreiro JF, Sá-Correia I. Genome-wide identification of Saccharomyces cerevisiae genes required for tolerance to acetic acid. Microb Cell Fact. 2010;9:79.

43. Mira NP, Teixeira MC, Sá-Correia I. Adaptive response and tolerance to weak acids in Saccharomyces cerevisiae: a genome-wide view. OMICS. 2010;14:525-40

44. Fernandes AR, Mira NP, Vargas RC, Canelhas I, Sá-Correia I. Saccharomyces cerevisiae adaptation to weak acids involves the transcription factor Haa1p and Haa1 p-regulated genes. Biochem Biophys Res Commun. 2005;337:95-103.

45. Tanaka K, Ishii Y, Ogawa J, Shima J. Enhancement of acetic acid tolerance in Saccharomyces cerevisiae by overexpression of the HAAl gene, encoding a transcriptional activator. Appl Environ Microbiol. 2012;78:8161-3.

46. Sasano Y, Watanabe D, Ukibe K, Inai T, Ohtsu I, Shimoi H, Takagi H. Overexpression of the yeast transcription activator Msn2 confers furfural resistance and increases the initial fermentation rate in ethanol production. J Biosci Bioeng. 2012;113:451-5.

47. Ma C, Wei X, Sun C, Zhang F, Xu J, Zhao X, Bai F. Improvement of acetic acid tolerance of Saccharomyces cerevisiae using a zinc-finger-based artificial transcription factor and identification of novel genes involved in acetic acid tolerance. Appl Microbiol Biotechnol. 2015;99:2441-9.

48. Kim D, Hahn J-S. Roles of the Yap1 transcription factor and antioxidants in Saccharomyces cerevisiae's tolerance to furfural and 5-hydroxymethylfurfural, which function as thiol-reactive electrophiles generating oxidative stress. Appl Environ Microbiol. 2013;79:5069-77.

49. Smith J, van Rensburg E, Görgens JF. Simultaneously improving xylose fermentation and tolerance to lignocellulosic inhibitors through evolutionary engineering of recombinant Saccharomyces cerevisiae harbouring xylose isomerase. BMC Biotechnol. 2014;14:41-57.
50. Pereira SR, Nogué VSI, Frazão CJR, Serafim LS, Gorwa-Grauslund MF, Xavier A. Adaptation of Scheffersomyces stipitis to hardwood spent sulfite liquor by evolutionary engineering. Biotechnol Biofuels. 2015;8:50.

51. Almario MP, Reyes LH, Kao KC. Evolutionary engineering of Saccharomyces cerevisiae for enhanced tolerance to hydrolysates of lignocellulosic biomass. Biotechnol Bioeng. 2013;110:2616-23.

52. Bajwa PK, Ho CY, Chan CK, Martin VJJ, Trevors JT, Lee H. Transcriptional profiling of Saccharomyces cerevisiae T2 cells upon exposure to hardwood spent sulphite liquor: comparison to acetic acid, furfural and hydroxymethylfurfural. Anton Leeuw Int J G. 2013;103:1281-95.

53. Lin FM, Qiao B, Yuan YJ. Comparative proteomic analysis of tolerance and adaptation of ethanologenic Saccharomyces cerevisiae to furfural, a lignocellulosic inhibitory compound. Appl Environ Microbiol. 2009;75:3765-76.

54. LV YJ, Wang X, Ma Q, Bai X, Li BZ, Zhang W, Yuan YJ. Proteomic analysis reveals complex metabolic regulation in Saccharomyces cerevisiae cells against multiple inhibitors stress. Appl Microbiol Biotechnol. 2014;98:2207-21.

55. Pereira FB, Teixeira MC, Mira NP, Sá-Correia I, Domingues L. Genome-wide screening of Saccharomyces cerevisiae genes required to foster tolerance towards industrial wheat straw hydrolysates. J Ind Microbiol Biotechnol. 2014;41:1753-61.

56. Cunha JT, Aguiar TQ, Romani A, Oliveira C, Domingues L. Contribution of PRS3, RPB4 and ZWF1 to the resistance of industrial Saccharomyces cerevisiae CCUG53310 and PE-2 strains to lignocellulosic hydrolysate-derived inhibitors. Bioresour Technol. 2015;191:7-16.

57. Chen Y, Stabryla L, Wei N. Improved acetic acid resistance in Saccharomyces cerevisiae by overexpression of the WHI2 gene identified through inverse metabolic engineering. Appl Environ Microbiol. 2016 (In press).

58. Aronesty E. ea-utils: Command-line tools for processing biological sequencing data. http://code.google.com/p/ea-utils. 2011. Accessed 1 Dec 2014.

59. Kong Y. Btrim: a fast, lightweight adapter and quality trimming program for next-generation sequencing technologies. Genomics. 2011;98:152-3.

60. Langmead B, Salzberg S. Fast gapped-read alignment with Bowtie 2. Nat Methods. 2012;9:357-9.

61. Anders S, Pyl PT, Huber W. HTSeq-a Python framework to work with highthroughput sequencing data. Bioinformatics. 2015;31:166-9.

62. Love M, Huber W, Anders S. Moderated estimation of fold change and dispersion for RNA-seq data with DESeq2. Genome Biol. 2014;15:550.

63. Feng $X$, Zhao H. Investigating host dependence of xylose utilization in recombinant Saccharomyces cerevisiae strains using RNA-seq analysis. Biotechnol Biofuels. 2013;6:96-106.

64. Saul DJ, Walton EF, Sudbery PE, Carter BLA. Saccharomyces cerevisiae whi2 mutants in stationary phase retain the properties of exponentially growing cells. J Gen Microbiol. 1985;131:2245-51.

65. Sudbery PE, Goodey AR, Carter BLA. Genes which control cell-proliferation in the yeast Saccharomyces cerevisiae. Nature. 1980;288:401-4.

66. Li BZ, Yuan YJ. Transcriptome shifts in response to furfural and acetic acid in Saccharomyces cerevisiae. Appl Microbiol Biotechnol. 2010;86:1915-24.

67. Kaida D, Yashiroda H, Toh-e A, Kikuchi Y. Yeast Whi2 and Psr1-phosphatase form a complex and regulate STRE-mediated gene expression. Genes Cells. 2002;7:543-52.

68. Yu H, Braun P, Yildirim MA, Lemmens I, Venkatesan K, Sahalie J, HirozaneKishikawa T, Gebreab F, Li N, Simonis N, Hao T, Rual JF, Dricot A, Vazquez A, Murray RR, Simon C, Tardivo L, Tam S, Svrzikapa N, Fan C, de Smet AS, Motyl A, Hudson ME, Park J, Xin X, Cusick ME, Moore T, Boone C, Snyder M, Roth FP, Barabási AL, Tavernier J, Hill DE, Vidal M. High-quality binary protein interaction map of the yeast interactome network. Science. 2008;322:104-10.

69. King L, Butler G. Ace2p, a regulator of (chitinase) expression, affects pseudohyphal production in Saccharomyces cerevisiae. Curr Genet. 1998;34:9.

70. Marion RM, Regev A, Segal E, Barash Y, Koller D, Friedman N, O'Shea EK Sfp1 is a stress- and nutrient-sensitive regulator of ribosomal protein gene expression. Proc Natl Acad Sci USA. 2004;101:14315-22.

71. Bähler J. Cell-cycle control of gene expression in budding and fission yeast. Annu Rev Genet. 2005;39:26

72. Ask M, Bettiga M, Duraiswamy VR, Olsson L. Pulsed addition of HMF and furfural to batch-grown xylose-utilizing Saccharomyces cerevisiae results in different physiological responses in glucose and xylose consumption phase. Biotechnol Biofuels. 2013;6:181. 
73. Wallace-Salinas V, Signori L, Li YY, Ask M, Bettiga M, Porro D, Thevelein JM, Branduardi P, Foulquié-Moreno MR, Gorwa-Grauslund M. Re-assessment of YAP1 and MCR1 contributions to inhibitor tolerance in robust engineered Saccharomyces cerevisiae fermenting undetoxified lignocellulosic hydrolysate. Amb Express. 2014;4:56.

74. Salusjärvi L, Kankainen M, Soliymani R, Pitkänen JP, Penttilä M, Ruohonen L. Regulation of xylose metabolism in recombinant Saccharomyces cerevisiae. Microb Cell Fact. 2008;7:18.

75. Matsushika A, Goshima T, Hoshino T. Transcription analysis of recombinant industrial and laboratory Saccharomyces cerevisiae strains reveals the molecular basis for fermentation of glucose and xylose. Microb Cell Fact. 2014;13:16.
76. Mumberg D, Müller R, Funk M. Yeast vectors for the controlled expression of heterologous proteins in different genetic backgrounds. Gene. 1995;156:119-22.

77. Nikawa Jl, Tsukagoshi Y, Yamashita S, Isolation and characterization of two distinct myo-inositol transporter genes of Saccharomyces cerevisiae. J Biol Chem. 1991;266:11184-91.
Submit your next manuscript to BioMed Central and we will help you at every step:

- We accept pre-submission inquiries

- Our selector tool helps you to find the most relevant journal

- We provide round the clock customer support

- Convenient online submission

- Thorough peer review

- Inclusion in PubMed and all major indexing services

- Maximum visibility for your research

Submit your manuscript at www.biomedcentral.com/submit
Biomed Central 